ISSN 2236-0859

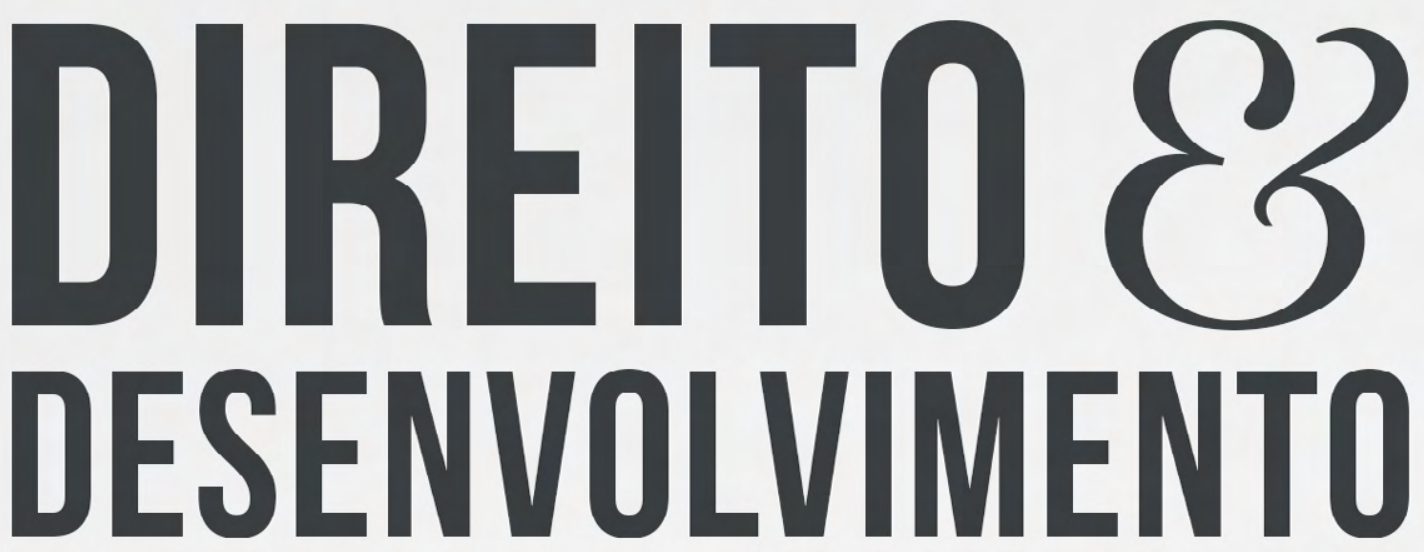

REVISTA DO PROGRAMA DE PÓS-GRADUAÇ̃̃O EM DIREITO MESTRADO EM DIREITO E DESENVOLVIMENTO SUSTENTÁVEL

\title{
APLICABLLIDADE DO COMPLIANCE COMO FERRAMENTA PARA DESENVOLVIMENTO SOCIAL E A REDUÇ̃̃ODO DÉFICIT ÉTICO DAS EMPRESAS
}

LIDIANA COSTA DE SOUSA TROVÃO VALTER MOURA DO CARMO 


\title{
APLICABILIDADE DO COMPLIANCE COMO FERRAMENTA PARA DESENVOLVIMENTO SOCIAL E A REDUÇÃO DO DÉFICIT ÉTICO DAS EMPRESAS
}

\section{APPLICABILITY OF COMPLIANCE AS A TOOL FOR SOCIAL DEVELOPMENT AND THE REDUCTION OF THE ETHICAL DEFICIT OF COMPANIES}

Recebido: $13 / 08 / 2018$

Aprovado: 20/10/2018

\author{
Lidiana Costa de Sousa Trovão* \\ Valter Moura do Carmo**
}

\begin{abstract}
RESUMO: A presente pesquisa tem por escopo analisar a aplicabilidade do compliance como ferramenta para redução do déficit ético das empresas, levando em consideração as relações que compõem as atividades exercidas dentro e fora do ambiente empresarial, como forma de nortear as atitudes daqueles que estão envolvidos nessa engrenagem. Em outro passo, analisa o reflexo das ações de integridade perante a sociedade, como instrumento de busca do desenvolvimento social, por meio da tomada de atitudes que a beneficiem. Outrossim, analisar-se-ão possíveis caminhos para alcançar função social/solidária da empresa diante da política de integridade do compliance, num panorama genérico de critérios pautados na busca desses objetivos, que devem ser orientados pelos princípios da ética, da solidariedade e da dignidade humana. Nesse contexto, serão observados os parâmetros utilizados para delimitar o exercício do direito de propriedade, do qual decorre o direito de exercer a atividade empresarial em termos constitucionais. Assim, diante da necessidade crescente da contenção do déficit ético nas empresas públicas e privadas, sob a análise econômica do direito, a prática do compliance surgiu no cenário econômico empresarial como forma de balizar e direcionar condutas, guiadas pela premissa de que à custa do sacrifício de valores éticos, o lucro perde seu valor. Daí porque a necessidade de desenvolver estudos nessa área em expansão, a fim de que as práticas internas possam compatibilizar-se com ações em nível mundial, que exigem cada vez mais ética e transparência em suas relações. Utilizar-se-á o método dedutivo, pesquisa qualitativa e artigos científicos sobre o tema em questão.
\end{abstract}

Palavras-chave: Compliance. Desenvolvimento social. Déficit ético. Função social da empresa.

\begin{abstract}
The aim of this research paper is to analyze the use of compliance as a tool for reducing the ethical deficit of companies, in regards to the relations that make up the activities carried out inside and outside the business environment, as a way of guiding the attitudes of those involved in those relations. Furthermore, it considers possible ways to achieve the company's social/solidary function in regards to specific policies, in a generic panorama of criteria based on the pursuit of these objectives, which must be guided by the principles of ethics, solidarity and human dignity. In this context, the parameters used to delimit the exercise of the right of ownership, on which is based the right to exercise business activities, as per Brazilian law. Thus, faced with the increasing need for the containment of the ethical deficit in public and private companies, under the economic analysis of the law, the practice of compliance arose * Graduada em Direito pela Universidade Federal do Maranhão - UFMA. Mestranda em Direito pela Universidade de Marília UNIMAR. E-mail: lidianacst@hotmail.com

** Doutorado em Direito pela UFSC (2016), tendo realizado o doutorado sanduíche na Universidade de Zaragoza (Espanha). Mestre em Direito Constitucional pela UNIFOR com período sanduíche na Universidade Federal de Santa Catarina - UFSC (2012). Professor Assistente da UNIMAR. Professor permanente do Programa de Pós-Graduação em Direito. Diretor de relações institucionais do CONPEDI. E-mail: vmcarmo86@gmail.com
\end{abstract}


in the business economic scenario as a way of guiding and directing behaviors, guided by the premise that profit loses its value when ethical values are sacrificed. That is why the need to develop studies in this expanding area, so that internal practices can be reconciled with actions at the world level, which require more and more ethics and transparency. The research carried out is qualitative, uses the deductive method, and scientific articles as sources.

Keywords: Compliance. Ethical deficit. Social function of the company.

\section{INTRODUÇÃO}

O estudo foi desenvolvido com o intuito de analisar a aplicabilidade do compliance como ferramenta para redução do déficit ético das empresas, levando em consideração as relações que compõem as atividades exercidas dentro e fora do ambiente empresarial, como forma de nortear e balizar as atitudes daqueles que estão envolvidos nessa engrenagem.

A investigação se pauta na forma como se dão as ações previstas nos regulamentos do compliance a serem aplicados nas empresas, públicas e privadas, diante de ações que possam minimizar alguns efeitos causados por práticas imoderadas no ambiente empresarial, que acabam por refletir na sociedade.

Diante da necessidade crescente da contenção do déficit ético nas empresas públicas e privadas, sob a análise econômica do direito, a prática do compliance surgiu no cenário econômico empresarial como forma de balizar e direcionar condutas, guiadas pela premissa de que à custa do sacrifício de valores éticos, o lucro perde seu valor.

Por meio da gestão de riscos, buscam-se aplicar práticas que resultem em respostas efetivas de prevenção, diminuição e exclusão da corrupção em suas diversas formas. Não há dúvida de que valores éticos devem balizar toda e qualquer atividade econômica, uma vez que a proteção jurídica das empresas só tem sentido quando suas atividades são pautadas na solidariedade social. Essa solidariedade permite o diálogo entre empresas privadas e entre estas e as empresas públicas, cujo ganho competitivo proporcionado pelo compliance atinge consideráveis índices de confiabilidade e permitem a observância do postulado da dignidade da pessoa humana do início ao fim do processo.

Cumprir a função social da empresa, portanto, mostra-se como principal fundamento das atividades que compõem o compliance, cujas metas são o enfrentamento da corrupção, das práticas abusivas, da deslealdade e do déficit ético, entendidas aquelas que ocorrem tanto dentro como fora da atividade empresarial, abrangendo as relações de engrenagem e sua imagem refletida na sociedade. Essas atitudes positivas da empresa engendram a perspectiva pelo desenvolvimento social, uma vez que cumprem a função social aquela que se esforça para atingir um objetivo útil em que haja proveito tanto para os envolvidos como para toda a sociedade.

Para a condução deste trabalho foi utilizada pesquisa qualitativa, doutrina nacional e artigos científicos sobre o tema em questão. Dividiu-se a pesquisa em momentos. Partiu-se da análise da função social/solidária da empresa e os problemas enfrentados para manter o equilíbrio do nível ético nas relações empresariais. Em seguida, analisou-se o contexto em que se insere o compliance e suas características como alternativa para contenção progressiva do déficit ético das empresas. Por fim, foi analisada a implementação do compliance nas empresas, sua evolução enquanto conceito na pós-modernidade e possível eficácia para solução de problemas estruturais graves. 


\section{FUNÇÃO SOCIAL/SOLIDÁRIA DA EMPRESA COMO MECANISMO PARA O DESENVOLVIMENTO SOCIAL}

Há muito se tem buscado um equilíbrio nas operações econômicas que circundam as esferas pública e privada, num incessante interesse em desvincular o perfil individualista, ou, muitas vezes, egoísta, daqueles que desempenham atividades privadas, e de algum modo fazê-las conciliar a vinculação privada ao desenvolvimento social e o respeito aos direitos fundamentais. Nesse contexto, o déficit ético das empresas decorre de anos de más condutas, de tolerância ou engajamento das corporações a essas práticas, fazendo-as perpetuar para além de padrões minimamente aceitáveis.

Num contexto histórico, ocorreram várias mudanças no direito de propriedade, típicas da dinâmica que acompanha as relações humanas. Assim (GONÇALVES; REZENDE, 2015, p. 53):

\footnotetext{
Ao longo do tempo, o conceito de propriedade sofreu várias alterações, numa tentativa de acompanhar as evoluções sociais. Dessa forma, no transcurso da história a propriedade exerceu várias funções, evoluindo da propriedade absoluta e individualista até a propriedade limitada pela função socioambiental dos dias atuais. Em geral, nas sociedades mais primitivas prevalecia o sentimento de coletividade, pois os homens viviam em tribos e os bens pertenciam a todos. Apenas em relação a bens móveis se verificava a propriedade privada.
}

Na evolução histórica brasileira pela busca do desenvolvimento social e afirmação dos direitos fundamentais, a Constituição Federal de 1988, com o passar do tempo, fez com que houvesse uma conscientização gradativa acerca da necessidade de abandonar o individual, num contexto egoístico, para um contexto plural, social, que pode beneficiar a todos indissociavelmente. Interessante notar que, ao indicar onde de fato emana o poder de praticar as efetivas modificações na sociedade, a $\mathrm{CF} / 88$ respaldou que é do povo (sociedade) de quem emana a verdadeira força motriz. É dizer que (NOGUEIRA; BENEVIDES, 2017, p. 82):

Com a elevação no nível de consciência geral da sociedade acerca da relevância dos direitos humanos, bem como da necessidade de devolver processos de organização e luta para afirmação, consolidação e ampliação dos direitos fundamentais, tanto no que diz respeito aos direitos civis e políticos quanto no concernente aos direitos econômicos, sociais, culturais e ambientais, há quem considere que a partir do Golpe Militar e da resistência que ocorreu em face do regime ditatorial que o sucedeu, houve o florescimento dos direitos humanos no Brasil. Destarte, tivemos com a Constituição de 1988 a consolidação de uma ampla gama de direitos fundamentais [...].

A evolução desse pensamento fez com que o exercício das boas práticas passasse a ser um ponto alcançável diante da atividade empresarial, pois toda essa dinâmica necessita do empenho daqueles que estão envolvidos direta ou indiretamente. Não se pretende desvirtuar o principal objetivo da atividade econômica - o lucro, porém, sua busca a qualquer custo acaba tendo, ao final, um custo muito maior. Não há apenas um prejudicado nessa relação dialética, quando se relega a segundo plano a solidariedade como possível solução para uma sociedade desigual, marcada por injustiças e pelo desnecessário sacrifício da dignidade humana.

A origem da noção de dignidade humana, consoante Landa (2015, p. 110):

La dignidad de la persona humana se asienta en un sistema de valores democráticos propios de la posición humanista que adoptó la cultura universal luego del Holocausto de la Segunda Guerra Mundial. Inicialmente se habló de un renacer del iusnaturalismo frente a una concepción positivista del hombre y del Estado de Derecho; sin embargo, fue 
la renovada teoría institucional la que logró darle el perfil de un principio constitucional y de un derecho fundamental.

$\mathrm{Na}$ Constituição brasileira, o princípio da dignidade humana perfilhou paradigmas existentes no direito constitucional alemão de 1959, cuja premissa se assenta na lógica da intangibilidade da dignidade do homem, devendo-se respeitá-la e protegê-la, obrigação de todo o poder público. Desse modo, "a Constituição Alemã elevou a proteção à dignidade humana a patamar máximo, ao estabelecê-la como direito absoluto", sendo de tal modo consagrado, que se afirma inclusive que referido princípio representa "o alfa-ômega do sistema constitucional de proteção das liberdades.” (FURTADO, 2015, p. 297).

Desta feita, seguindo o constitucionalismo moderno, "conclui-se que dar fundamento ao Estado na dignidade da pessoa humana patenteia o reconhecimento do valor do homem enquanto ser livre", e franqueia ao Estado o reconhecimento de "ter suas pilastras na observância do princípio em baila em favor do ser humano, abrangendo tal princípio não somente os direitos individuais, mas os direitos outros, de natureza econômica, social e cultural" (FURTADO, 2015, p. 299).

Tal princípio, está assentado em tantos outros valores, a começar na preservação e direito à vida, a que a ordem econômica tenha por escopo dar condições para que todos além de vida, possa gozá-la dignamente. Da forma como a dignidade humana está insculpida na nossa Carta Política, nas palavras de Furtado (2015, p. 299-300):

[...] É uma referência constitucional unificadora de todos os direitos fundamentais, devendo, por tal razão, seu conteúdo ser compreendido com caudalosa valoração que encare seu sentido normativo-constitucional, afastando-se, tanto quanto possível, uma noção superficial da essência do próprio homem, de tal sorte que se arrede qualquer ideia apriorística do homem.

Ingo Sarlet (2007, p. 364), enuncia que a dignidade humana é algo tão latente e vivenciado pelo ser humano, que não há dificuldade em se identificar com clareza as situações em que ela é agredida, embora haja "uma pauta exaustiva de violações da dignidade". Desse modo, acrescenta o referido autor, "independe das circunstâncias concretas, já que inerente a toda e qualquer pessoa humana, visto que, em princípio, todos [...] - são iguais em dignidade, no sentido de serem reconhecidos como pessoas [...]" (SARLET, 2007, p. 367), ainda que se portem de forma desigual. A compreensão da dignidade humana no âmbito da necessidade de respeitar o outro, inclusive nas relações privadas, deverá ser objeto a ser considerado.

Considerando o paradigma ético levantado, é dizer, ainda, que "numa sociedade desigual como a brasileira, conservadora e patrimonialista, com uma indisfarçável dificuldade para reconhecer as diferenças sociais e combatê-las", impossível não admitir que "o princípio da dignidade da pessoa humana é instrumento eficaz para que se impeça a coisificação do homem." (RODRIGUES; LIMA, 2015, p. 344).

O reconhecimento da necessidade de se fazer algo pelo outro, e desse modo pela sociedade, fez com que o cumprimento da função social refletisse também a busca pelo desenvolvimento social, cujo estandarte é o de acompanhar a evolução da própria sociedade. Não é razoável esperar que as relações humanas sejam, por si sós, eleitas ao desenvolvimento. A busca pela melhoria nessas relações, a exemplo daquela fincada entre empresário e sociedade é, além de inevitável, passível de ser moldada para que não haja nem retrocessos nem excessos.

Nesse sentido é o entendimento de Pessoa (2010, p. 70), ao afirmar que: 
Com a modernidade, o paradigma se desloca para o indivíduo, para a pessoa humana, verdadeira visão antropocentrista. As Constituições modernas (e contemporâneas) são documentos políticos que partem da limitação à atuação do poder estatal, no sentido de proteger as pessoas.

Aqueles que buscam o lucro, como termo preponderante da atividade econômica, consideram que, postas todas as cartas na mesa, aquele que vencer (a qualquer custo) será o que mais bem soube desempenhar seu papel empresarial. Aliado a esse pensamento, estarão à margem de qualquer pensamento capitalista o que haverá no futuro, a que custo será faturado o lucro do presente, a que preço terá às pessoas e ao mundo para gerações futuras.

Entretanto, existe uma agradável corrente de expectativas que está levando a aproximação das boas práticas à função social do direito privado, como início de um raciocínio que leva a refletir sobre seus interesses na perspectiva da solidariedade, como forma de mostrálo legítimo diante do interesse social. Esse pensamento decorre da mudança de paradigma acerca da própria função social do direito, da justiça, "como valor ideal, hoje dá sentido social ao comportamento dos particulares, significando isso que cada um, a partir da noção jurídica de solidariedade, está obrigado a assumir sua respectiva responsabilidade cívica, cooperando para o bem-comum." (CARDOSO, 2010, p. 184).

Percebe-se, portanto, que a evolução do pensamento moderno acerca da realidade que estava sendo apresentada fez com que houvesse a necessidade de mudar os paradigmas para alcançar posterior êxito no exercício das atividades econômicas privadas. Veja-se que essa realidade "mostrava a diferença cada vez maior entre a igualdade formal e a desigualdade material, que afastava as classes menos favorecidas" (CARDOSO, 2010, p. 184), de modo a isolálas da possibilidade de serem beneficiadas, ou, pelo menos, não atingidas pela avalanche de consequências da busca do lucro a qualquer custo. O déficit ético, nesse passo, é enorme, a ponto de ofuscar os efeitos dessa prática. Não se enxerga além e as premissas antecedentes são tão fortes que não se vê o resultado do que é feito ou deixado de fazer.

Parte da literatura entende que a função social da empresa alcança o modo como essa responsabilidade é pulverizada na empesa. Nesse sentido, salutar o entendimento de Alzaga Villaamil (2009, p. 10):

\footnotetext{
Entendemos por Responsabilidad Social de la Empresa (RSE) el compromiso que asume una empresa de actuar de forma positiva y comprometida en la consecución de sus objetivos económicos y financieros, creando valor para sus accionistas, y teniendo en cuenta el efecto que esas acciones tienen en los grupos de interés que conforman y dan sentidoa la propia realidad empresarial. La RSE se practica cuando las compañías integran los asuntos sociales y medioambientales en sus negocios y cuidan sus interacciones con los ciudadanos y con los grupos de interés o stakeholders. Una empresa es responsable si de manera voluntaria procura que sus decisiones empresariales tengan un impacto positivo sobre los grupos de interés que la conforman: accionistas, empleados, clientes, proveedores, medio ambiente y sociedad en general.
}

Dada sua atual mobilidade, o direito privado, apesar de consubstanciar "uma situação de poder", pode adequar-se "às transformações dos valores dotados pela sociedade, de maneira que ela tem a vantagem de tornar o Direito Privado um sistema móvel, voltado ao atendimento dos direitos fundamentais num sentido concreto". (CARDOSO, 2010, p. 185). Isso implica dizer que, pelo princípio da solidariedade, há que se observar os interesses difusos e coletivos, mesmo que haja normas que determinem que sejam observadas uma ou outra conduta. Ainda com Cardoso (2010, p. 187), "essa nova feição, articulada por noções de igualdade, equidade e justiça para todos, interage o indivíduo à sociedade, e a atribuição de uma 'sociedade' ao 
direito faz com que ele retome seu fim de construir uma sociedade justa, mormente no que diz respeito ao Direito Privado".

Dentro dessa asserção, "princípios como o da probidade e da boa-fé traduzem um valor ético que se exprime em um dever de lealdade e correção nas relações entre particulares [...]", e, principalmente, "a equidade como princípio ético que orienta a realização do direito no sentido de evitar-se uma injustiça" (CARDOSO, 2010, p. 187). Importa mencionar que a ética, como vetora de toda atividade interpessoal, tem o homem como principal destinatário e é dele a missão de aplicá-la na sociedade e para a sociedade, cujo objetivo permanente é resguardar as pessoas como parte de um todo coletivo, indissociável.

Em outras palavras, a função social/solidária da empresa liga-se diretamente ao desenvolvimento social, na medida em que "possui uma conotação diversa, pois agrega uma ideia de que se deve também colaborar, por meio do negócio, para o desenvolvimento da sociedade, numa perspectiva de auxílio às pessoas". Nessa perspectiva, "a função solidária da empresa é aquela que traz uma contribuição valorosa para o desenvolvimento social." (SANTIAGO; CAMPELLO, 2016, p. 136).

Boas práticas de integridade são fundamento para contribuição do desenvolvimento social como reflexo da função social da empresa. Numa herança histórica da mudança do panorama empresarial, fincada pelo crescimento de transnacionais igualmente responsáveis pela promoção do desenvolvimento social, as empresas, ao exercerem a atividade econômica, assumiram a tarefa de cumprir suas obrigações perante seus funcionários, fornecedores, fisco e, portanto, toda a sociedade, dividindo o contencioso com o Estado, igualmente responsável pela proteção e promoção social. Acerca do assunto, Feitosa (2013, p. 106) aduz que:

No domínio político-econômico, pode-se atestar ter ocorrido, ante o enorme
crescimento das empresas transnacionais, severa restrição na capacidade dos Estados
nacionais de operar seus instrumentos de proteção e promoção social. As corporações
transnacionais, diferentemente das antigas multinacionais, passaram a se estruturarem
em feixes de empresas, [...] se espalharam pelo mundo impactando o poder político
dos Estados nacionais e a capacidade de proteção jurídica de seu sistema de direitos e
garantias, nos campos dos direitos econômicos, sociais e culturais (DESC), colidindo
em direitos trabalhistas, previdência e assistência social, educação, saúde, entre outros.

A empresa, diante do dever constitucional de buscar cumprir sua função social, representa papel determinante para que, acompanhada de ações estatais, possa contribuir de forma decisiva para o desenvolvimento social. A política do compliance se molda na transformação para operacionalizar suas atividades, fazendo com que busque também objetivos sociais, como a diminuição das desigualdades. Volta-se à afirmação de que a atividade empresarial, com a busca precípua do lucro, ao cumprir a função social da empresa, o faz por meio do "[...] princípio da compatibilização do interesse privado com o coletivo e o difuso" (SILVEIRA; NASPOLI, 2013, p. 131), e, nesse sentido:

[...] pode-se dizer que, na atual ordem econômica brasileira, os interesses coletivos e difusos não podem oprimir os membros do próprio grupo; ou seja, os interesses individuais. Pelo contrário, deve-se compatibilizar o interesse coletivo com a livreiniciativa e o princípio da liberdade econômica, haja vista que a liberdade privada não pode ser suprimida em um sistema capitalista. (SILVEIRA; NASPOLI, 2013, p. 131)

Todos esses aspectos precisam dialogar, para que haja uma harmonia na atividade econômica. Os objetivos a serem traçados necessitam, precipuamente, beneficiar a sociedade como um todo, de modo a promover o desenvolvimento social e consequentemente o humano. Não há como dissociar a atividade empresarial do dever de promoção social por meio da função 
social, pois, do contrário, a finalidade da pessoa jurídica estaria vazia. De nada vale o lucro às custas da dignidade humana.

\section{COMPLIANCE COMO FERRAMENTA PARA DIMINUIÇÃO DO DÉFICIT ÉTICO DAS EMPRESAS}

Dentro de todo esse panorama traçado, é importante estabelecer diretrizes a serem seguidas, pontos a serem delineados, arremates a serem feitos. Parece tarefa fácil, mas, na verdade, pela dinâmica atual do mercado, alcançar um nível mínimo de ética na atividade empresarial se tornou um objetivo muito complicado de ser alcançado. Não pela atividade em si, e nem pela vontade do empresário em ferir as regras de boa conduta, mas pela necessidade de alcançar metas e obter lucros ainda maiores. Essa vivacidade e ambição não são algo que seja totalmente despojado pela doutrina, pelo contrário, a atividade empresarial se faz essencialmente do lucro, porém, não significa que esses dois objetivos não possam ser alcançados paralelamente.

Mas, em que momento esse equilíbrio deve ser expressado? O princípio ético não está sozinho nessa empreitada. O Código Civil está assentado em outros princípios, além daqueles que emanam do prisma constitucional. Assim é a assertiva de Santiago e Campello (2016, p. 128129), ao afirmarem que "o princípio da socialidade é um dos três princípios basilares do novo Código Civil, sendo os outros dois o princípio da eticidade e o princípio da operatividade. Isso é assim, exatamente, em consequência da mudança de visão que condenou o individualismo exacerbado à morte".

Não é demais dizer que o individualismo, ou até o egoísmo das relações privadas foi aniquilado com o advento do Código Civil de 2002. Não há mais chance de pensar o contrário, de agir ao contrário. A base principiológica não dá espaço para que seja pensado diferente e, portanto, quem na pós-modernidade desejar exercer atividade econômica no Brasil deverá cumprir a lei e reconhecer que os seres humanos compartilham uma destinação comum.

Adverte Cardoso (2010, p. 193) sobre a amplitude dos institutos privados à luz dos ditames constitucionais, como forma de afastar a ideia de que Constituição e Código Civil são "esferas estanques, fechadas em si mesmas":

\footnotetext{
Propriedade privada, contrato, empresa, família, interesses difusos e responsabilidade civil são tratados pela (sic) Direito Privado contemporâneo como instrumento da economia num mundo compartilhado por todos, e, logo, precisam ter função social, sob pena de perversão da própria ordem econômica capitalista, pois aquela contrapõese ao abuso de direito, obrigando o proprietário a utilizar seu patrimônio na forma de interesse coletivo.
}

O nível ético, portanto, decorre da necessidade de pôr em prática os diversos limites impostos ao direito de propriedade, e como consequência, a obrigação de dar função social a ela. Desta feita, a função social da empresa, como derivativo da função social da propriedade, num contexto privado, externa essa necessidade de, como dito acima, obrigar o proprietário a utilizar seu patrimônio na forma de interesse coletivo. Esse coletivo decorre de uma tendência natural do homem, cuja sociabilidade é indispensável para a vida em sociedade e para o exercício de suas atividades. Dentro dessa nova modernidade "há uma nova empresarialidade fundada na função social e na boa-fé objetiva, tendo por finalidade: geração de um valor econômico agregado; serviço à comunidade; desenvolvimento das pessoas que a integram e capacidade de continuidade." (DINIZ, 2012, p. 49). 
A preservação de níveis mínimos de ética nas empresas determina os rumos das atividades empresariais e, por consequência, das transações econômicas traçadas dentro dessa relação plural. É dizer, inclusive, que a corrupção, ou, simplesmente, déficit ético, contamina não só as pessoas que estão praticando ou deixando que se pratique, mas permite que consumidores, contribuintes e a sociedade em geral seja prejudicada. Na mitigação da impessoalidade nas licitações com o poder público, versada em favorecimentos pessoais e na frustração da competição, ou mesmo nas relações entre particulares, quando ambos maculam transações com pessoas jurídicas ao invés de pessoas físicas, a fim de recolher aos cofres públicos alíquota mais favorável de imposto de renda. Essas atividades possuem um efeito deletério devastador, que, cedo ou tarde, atinge a sociedade como uma avalanche.

Dentro desse panorama, o empresário exerce uma função importante no que diz respeito ao grau de confiabilidade que a sociedade deposita na empresa e à responsabilidade que a pessoa jurídica deve refletir. Desse modo, além de pequenas ações do cotidiano, as empresas adotam o balanço social, que "é feito exatamente para dar publicidade e transparência. Através dele é possível a sociedade acompanhar e avaliar o nível ético de determinada corporação.” Esse balanço é adotado por empresas que cumprem a função social "como instrumento de gestão e informação para os acionistas e toda a sociedade. Esse instrumento revela as ações que foram desenvolvidas no campo socioeconômico. É uma prestação de contas aos stakeholders." (BARACHO; CECATO, 2016, p. 124).

Não se pode deixar de analisar essa sociabilidade ética no contexto do objetivo primordial da atividade empresarial, o lucro, quando a própria constituição consagrou o capitalismo como sistema econômico, tendo em vista que dar função social à empresa não inviabiliza a atividade lucrativa. Nesse sentido são os ensinamentos de Maria Christina de Almeida (2003, p. 145):

[...] é importante dizer que essa instituição não irá renunciar à sua finalidade lucrativa ao voltar-se para a sua função social. É que as empresas, na atualidade, acabam sendo tão responsáveis quanto o Estado, no que se refere a assegurar os direitos individuais do cidadão, dando-se ênfase na melhora não apenas do aspecto econômico, mas também do social e da comunidade na qual está inserida, o que, em última análise, beneficia todas as partes.

Com essa obrigação legal de promover ações coletivas, a empresa tem se esforçado para atingir esses objetivos sem descuidar da promoção de sua imagem. A questão se mostra tormentosa quando, ainda que haja a promoção dessas ações buscando impelir a função social da empresa, o resultado dessas ações dá forte conotação antiética, pois, na verdade, o que se busca não é a satisfação dos interesses coletivos, mas tão somente o ensejo de evidenciar a empresa. Praticar uma conduta ética, observado o princípio da solidariedade, nas condições sociais e competitivas do mundo empresarial moderno, não pressupõe um afastamento dos objetivos lucrativos de uma sociedade capitalista.

Diniz (2012, p. 47) aponta que "a função social do contrato de sociedade e da propriedade empresarial busca a boa-fé objetiva do empresário (individual ou coletivo), a transparência negocial e a efetivação da justiça social", de modo que o "princípio da boa-fé objetiva privilegia o respeito à lealdade, requerendo do empresário um padrão de conduta, que tenha como standard 'o bom homem de negócios', que deve ter o dever de diligência e cuidado próprio na condução de seu interesse.”. Acrescenta a autora que (2012, p. 47):

[...] eis a razão pela qual Alberto Simão Filho afirma, acertadamente, que o empresário deve buscar um ponto de equilíbrio ("ótimo de Pareto"), obtendo o máximo de eficiência social, fazendo com que os custos sociais derivados das atividades mercadológicas sejam iguais aos benefícios sociais alcançados. 
Atingir a função social por meio da observância ética da atividade empresarial não é tarefa fácil, porém, não é impossível. Há possibilidade de que os efeitos negativos, ou externalidades, ou deseconomia externa (utilizados por Maria Helena Diniz como termos sinônimos) por meio de mecanismos de compensação, e nesse contexto (DINIZ, 2012, p. 48):

\footnotetext{
Mediante um processo de internalização da externalidade por meio da economia do bem-estar social, considerando a externalidade como uma falha do mercado, cabendo, então, ao Estado corrigi-la pela tributação, ou da análise econômica do direito, pela qual os próprios interessados negociam a internacionalização da externalidade, fazendo uso do direito de reduzir os custos da transação.
}

É nesse ponto que se insere a possibilidade de utilização do compliance como ferramenta para diminuição do déficit ético empresarial, levando-se em conta que ele pode ser utilizado como "uma proposta de standard comportamental, fundada na ética, nos costumes comerciais e no princípio da boa-fé objetiva, para uma nova empresarialidade, fazendo, inclusive, com que a responsabilidade social seja uma opção consciente do 'bom empresário"” (DINIZ, 2012, p. 55). Embora o termo posto em evidência seja questionado atualmente, por ter sido travestido para enaltecer unicamente a imagem da empresa, as premissas para um bom exercício da atividade empresarial estão pautadas em ações responsáveis, éticas e que leve em consideração o princípio da função social da empresa.

O que se pôde observar, até aqui, é que há sempre uma grande dialética entre o que se pode e o que se deve fazer na atividade empresarial. A busca pela excelência na função social da empresa, por muitas vezes gerar custos, não é interessante para maioria dos empresários. Contudo, pela pressão social exercida e pelo dever legal de dar à propriedade uma função social, acabam por digerir as externalidades negativas e tentar minimizá-las em outros aspectos, apesar de, muitas vezes, como dito alhures, não conseguirem esconder a nódoa da insensatez antiética.

Se é moda ou não, a implementação do compliance, na verdade, traduz diversas maneiras de implementação de ações que possam diminuir o déficit ético das empresas, e, se porventura o termo em si não evolua, ou com o tempo seja superado por outra mais moderna, o que realmente importa é que servirá para auxiliar na busca por uma sociedade mais justa e solidária.

Não é dizer que o empresário não opta por alcançar ou não a função social da empresa, dentro de um panorama de obrigações constitucionais. Consoante Cardoso e Carmo (2017, p. 145) "a função social da empresa é o corolário de uma ordem econômica que, embora composta por vários princípios, possui o intento comum de garantir a todos uma existência digna, conforme os ditames da justiça social", e, desse modo, não lhe é dada a escolha de ter ou não uma finalidade social diante de "responsabilidades perante a sociedade como um todo", na qual "deverá ser responsável e exercer suas atividades com preocupação com o interesse social (sua finalidade)" (CARDOSO; CARMO, 2017, p. 145).

Adefinição de compliance está muito associada à ideia de integridade e comprometimento nas relações empresariais públicas e privadas, nas suas diversas modalidades, à luz do regramento previsto na Lei n. 12.846/2013, a chamada Lei Anticorrupção, cujas diretrizes são apresentadas com o intuito de auxiliar as empresas a construir ou aperfeiçoar boas práticas. Estas, estão intrinsecamente relacionadas ao exercício de atividades pautadas na ética, com aplicação de medidas anticorrupção.

O termo integridade na proposta do compliance alcança diversos outros aspectos, pois uma empresa íntegra, de ações e atividades íntegras, todas pautadas na boa-fé e na ética, demandam que todos esses elementos sejam observados conjuntamente. Ética e boa-fé 
são características indissociáveis ao termo integridade, que induz ao entendimento de que para colocá-las em prática é necessário que haja prévia articulação de toda a corporação, um comprometimento dos diversos setores e o desejo que sejam perenes e não apenas externadas em determinadas situações.

Grandis (2017) analisa a responsabilidade social da empresarial, para posteriormente confrontá-la com o compliance, apontando similaridades e diferenças, e ao final indicar seu ponto de convergência:

[...] as similariades (SIC) entre Compliance e RSE são evidentes: o fundamento de ambos são os valores éticos e seus beneficiários são a empresa e seus stakeholders. No entanto, eles diferem quanto aos objetivos principais que, nos programas de Compliance são especialmente prevenir fraudes, corrupção, a lavagem de dinheiro e o financiamento do terrorismo, enquanto o da RSE é contribuir para uma sociedade mais justa e para um ambiente mais limpo. Neste novo contexto, o profissional de Compliance atua como verificador das ações de RSE, de modo a afastar eventuais conflitos de interesse ou, até mesmo, o uso da área para práticas indevidas, por exemplo, doações para instituição de agente público ou político em contrapartida a benefício em contratação pública ou como mecanismo de lavagem de dinheiro.

Em defesa da responsabilidade social empresarial (RSE), a autora arremata afirmando que "a área de RSE não se configurou mero modismo, ao contrário, permanece em voga, porém agora com um novo aliado para orientar a tomada de decisões e a definição de estratégias que garantam não só o atendimento do objetivo final das ações socioambientais, mas, também, a preservação da reputação da empresa/entidade" (GRANDIS, 2017, p. 57).

Sem embargo de outras modalidades de compliance, as responsabilidades apontadas no seu âmbito atingem as esferas penal, civil e trabalhista, uma vez que, em sendo a pessoa jurídica uma cadeia de múltiplas responsabilidades, os seus reflexos de uma forma ou de outra atingirão todos os envolvidos no processo econômico. Desse modo, acerca do criminal compliance, salienta Rotsch (2012, p. o6) "un concepto de Compliance dirigido a una completa evitación de la responsabilidad penal debe por lo tanto tomar en consideración la empresa en su conjunto, en su caso a todos los trabajadores de la empresa y no sólo a la cúpula directiva.", uma vez que essa suposta evasão "[...] sería entonces un mero traslado de la responsabilidad que afectaría penalmente a otros sujetos, lo cual desde el punto de vista empresarial puede ser igualmente desastroso." (ROTSCH, 2012, p. o5).

Nesse mesmo passo, preocupado em alinhar as novas práticas de mercado no contexto do compliance às relações entre o poder público e as empresas privadas, nos mais diversos setores, e ainda, pela exigência de mercados internacionais na comprovação de atividades íntegras, foi elaborado pela Controladoria Geral da União, uma espécie de cartilha, intitulada "Programa de Integridade", com o objetivo de balizar e propor diretrizes para pautar as atividades por ela desempenhadas. Essa cartilha prevê a ética como paradigma a ser observado, conforme texto que segue:

\footnotetext{
Os padrões de ética e de conduta representam o comportamento esperado de todos os funcionários e dirigentes da empresa. É conveniente que tais padrões sejam reunidos em documento único, geralmente denominado código de ética ou de conduta. De qualquer forma, é perfeitamente possível que a empresa possua dois documentos complementares: um que trate de valores e princípios da empresa (código de ética) e outro que explicite a conduta a ser seguida pelos membros da empresa (código de conduta). O importante é que tais padrões de comportamento sejam claros, sejam seguidos por todos, e que se encontrem também amplamente acessíveis ao público externo, em especial aos parceiros de negócio e clientes. (BRASIL, 2015, p. 14)
} 
O compliance, portanto, exprime a necessidade de compatibilizar as diversas ações de integridade dentro de padrões éticos e de conduta para que cada organização, de acordo com suas peculiaridades, com o engajamento de toda a corporação. Essas ações devem ser, de início, desenvolvidas no ambiente interno, mas com vistas a abranger também as ações fora da empresa, nas suas relações com outras empresas, fornecedores e mesmo com o poder público. Nesse sentido (BRASIL, 2015, p. 15):

Vários dos riscos aos quais a empresa está submetida impõem a necessidade de estabelecimento de normas sobre como os seus representantes devem agir quando em contato com agentes públicos. Uma política clara e efetiva sobre relacionamento com o setor público é capaz de mitigar riscos relacionados à participação em licitações e contratos administrativos; ao pagamento de tributos; à obtenção de licenças, autorizações e permissões; a situações de fiscalização ou regulação; à contratação de atuais e ex-agentes públicos, entre outros.

Sob esse aspecto o relacionamento de empresas privadas com empresas públicas demanda uma atenção ainda maior, pois existem várias formas de corrupção que podem desequilibrar essas relações e, principalmente, ferir o princípio da isonomia. Um deles é a necessidade de atenção e cuidado com os registros contábeis da empresa, uma vez que são fontes essenciais para identificar impropriedades, como "suborno, assim como outras práticas ilícitas, [...] geralmente disfarçado contabilmente em pagamentos legítimos como comissões, consultorias, gastos com viagens, bolsas de estudo, entretenimento, etc." Desse modo "é importante que os registros sejam confiáveis, de forma que permitam o monitoramento das despesas e das receitas, facilitando a detecção de ilícitos." (BRASIL, 2015, p. 17). Essas boas práticas se estendem a todos os setores da empresa, com características próprias e, também, a diversas outras práticas dessas entre si, no âmbito privado, e delas com o poder público.

Além disso, importante destacar que, a fim de ampliar a possibilidade de tomar ciência de condutas antiéticas, a empresa deve, de acordo com o programa de integridade, ou simplesmente compliance, implantar canais de denúncia, mediante avaliação do modo como essas informações serão feitas. Entretanto, deve a empresa se preocupar em manter o anonimato dos denunciantes, a fim de proibir a retaliação. Outrossim, "é desejável que a empresa tenha meios para que o denunciante acompanhe o andamento da denúncia, pois a transparência no processo confere maior credibilidade aos procedimentos." (BRASIL, 2015, p. 21).

Vale ressaltar que a necessidade de conter o déficit ético das empresas é de nível mundial, pois "[...] as empresas estão tendo que promover uma junção entre moralidade, publicidade, legalidade, eficiência, impessoalidade, proporcionalidade e responsabilidade objetiva. Princípios estes tradicionalmente tratados no espectro do Direito público.". (GABARDO; CASTELLA, 2015, p. 142-143). Partindo-se da análise econômica do direito, "igualmente não deve ser ignorada a gravidade do déficit ético que acomete o funcionamento das instituições públicas e privadas", fazendo-se necessária "a partir da junção destas duas crises, [...] cogitar-se também de análise jurídica da economia, adotada como premissa a de que a busca do lucro não justifica o sacrifício de valores éticos" (PEREIRA JÚNIOR; MARÇAL, 2017).

Assim, o principal enfoque nos esforços para diminuição do déficit ético se dá em razão da preservação do dever de dar função social à empresa, pois "é o principal fundamento dos programas de compliance, tão necessários à formação de uma nova cultura que relativize o lucro, submetendo-o à ética nos negócios, seja quando empresas privadas negociam entre si ou quando negociam com o estado." (PEREIRA JÚNIOR; MARÇAL, 2017).

Porém, muito mais que a vaidade de implantar um programa de compliance para exibir um selo de qualidade/honestidade, é o real sentido de cumpri-lo, cuja qualidade ética se sobrepõe a qualquer um dos adjetivos mercadológicos que a empresa possa alcançar. Além 
disso, "[...] a mera busca pelo lucro não garante sustentabilidade econômica, no sentido de permanência da empresa ao longo dos anos", não obstante ao fato de que "a sociedade contemporânea vem exigindo da empresa uma postura de responsabilidade pelos resultados paralelos de sua atividade. É nesse ponto que se inserem-se imbricam-se ética empresarial e responsabilidade corporativa." (SILVEIRA; RIBEIRO, 2015, p. 48).

É importante destacar que o emprego da ética nas ações empresariais se volta para os resultados, a fim de demonstrar um valor para a sociedade como a respeito dos impactos de suas atividades, dentro das externalidades negativas que já foram mencionadas anteriormente. Esse exercício ético é corolário do princípio da função solidária, do qual a empresa não pode ficar alheia. Essa nova ordem de valores, alavancada pela política do compliance, permite que esses elementos sejam compatibilizados e possam caminhar em harmonia. Desse modo (SILVEIRA; RIBEIRO, 2015, p. 51):

A constatação do surgimento de outra ordem de valores que impõe à empresa a satisfação dedemandasem favordos interessados ou afetados porsua atuação evidencia quea função solidária (inserida na terceira dimensão dos direitos humanos) está se desdobrando sobre parâmetros de ética, como conteúdo orientador da responsabilidade empresarial. Evidencia ainda que a absorção desses valores como integrante da responsabilidade empresarial tem-se se realizado o como forma de garantir a sustentabilidade da empresa, no sentido de sua permanência na sociedade.

As ferramentas oferecidas pelo compliance se mostram bastante eficientes no cenário atual. As tentativas de minimizar anos de descaso em relação ao déficit ético nas empresas incluem a oportunidade de reverter a imagem deletéria encontrada no mercado e aplicá-las para alcançar um nível mínimo em relação à função social/solidária da empresa. As relações ainda se encontram arranhadas, mas o intuito de mudança e os passos até aqui alcançados já representam um grande avanço, num contexto de busca incessante pela valorização humana.

Cabe destacar que uma vez implantada a política anticorrupção do compliance, trará benefícios a todos os envolvidos na corporação e na sociedade, pois a aumentará a confiabilidade perante investidores e trará maior credibilidade ao mercado. Essas são duas grandes razões para que as empresas se sintam confortáveis e convencidas de que aplicar um paradigma ético lhe trará muitos benefícios e a colocará adiante daquelas que não adotam a mesma postura.

Perseguir a excelência nas relações empresariais está longe de ser um objetivo facilmente alcançado. Porém, buscar melhorar cada vez mais, a fim de que a sociedade seja beneficiada sem que haja o sacrifício irretratável do lucro (inversa à inicialmente apresentada), pois tal situação não representa nenhum avanço, pelo contrário, só deixará exposta à reafirmação as anedotas mais pessimistas em relação ao compliance.

\section{COMPLIANCE, A RESPONSABILIZAÇÃO DAS EMPRESAS E A BUSCA PELA EXCELÊNCIA EM SUAS ATIVIDADES}

A prática reiterada e abusiva que compõe um conjunto de ações direcionadas na atividade empresarial, colaborando com o aumento do déficit ético, não raras vezes culminam com a imposição de penalidades, a depender do tipo de ilegalidade praticada pela empresa. Os programas de compliance auxiliam o empresário a ter um melhor controle sobre suas atividades de modo que todos os setores possam exercer seu mister pautados numa conduta ética e voltada para preservar a função social da empresa.

Não obstante, é inegável que os programas de compliance podem alcançar a possibilidade de diminuição das multas ou a mediação na celebração de acordos de leniência 
quando a empresa incorre em alguma irregularidade. Por outro lado, não menos importante, tem o condão de projetar proveitos e solver prejuízos a longo prazo, uma vez que, devido à engrenagem em que se inserem, tais problemas comprometem os mais diversos setores da empresa, onde um não funciona sem o outro na questão da integridade.

No Brasil, a legislação de maior relevância é a Lei Anticorrupção n. 12.846/13, porém, ela só se aplica a danos praticados em face da administração pública. Antes dela, a responsabilização ficava a cargo do direito penal e atingia, unicamente, a pessoa física, pois não havia previsão de responsabilização da pessoa jurídica no nosso ordenamento jurídico, salvo para crimes ambientais (Lei 9.605/1998), e como vetor antecedente, a previsão constitucional do $\S 3^{\circ}$ do art. 225. Por esse prospecto, e de acordo com Xavier (2015, p. 45):

\begin{abstract}
A Lei no 12.846/13 prevê pesadas sanções às condutas ilícitas, a maioria de caráter punitivo indenizatório e natureza pecuniária. Assim, caso seja constatada a prática de condutas consideradas lesivas à Administração Pública, a pessoa jurídica se sujeitará às sanções administrativas ali previstas, quais sejam: multa que pode alcançar $20 \%$ do faturamento bruto do último exercício financeiro, ou entre $\mathrm{R} \$ 6.000,00$ (seis mil reais) e R\$6o.ooo.ooo,oo (sessenta milhões de reais), caso não seja possível estimar seu faturamento, publicação da decisão condenatória, e inserção da decisão condenatória em um cadastro a ser criado, o Cadastro Nacional de Empresas Punidas (CNEP) [...].
\end{abstract}

O compliance existe antes mesmo de ser editada a Lei anticorrupção. Porém, foi ela que impulsionou e fez com que os envolvidos nesse circuito se interessassem em cumprila, fazendo com que diversas áreas se preocupassem com ela. A partir daí outras iniciativas surgiram (MENDES; CARVALHO, 2017, p. 26):

O fortalecimento do combate à corrupção e a cartéis, em um círculo virtuoso, levou a novas iniciativas do governo para conferir relevância ao tema - entre elas, destaca-se a edição do Decreto 8.420/2015, que veio regulamentar a Lei Anticorrupção e, em matéria de compliance, trouxe parâmetros bastante sobre como tais programas serão avaliados pela administração.

Com a indicação da lei para que as empresas implementem programas de integridade, visando diminuir riscos de aumento do déficit ético para torná-la mais transparente e confiável, aumentou a capacidade dessas corporações em materializar um perfil concorrencial de qualidade, cuja determinação se dá pela capacidade de negociar de maneira justa e limpa. Esse relacionamento derivado da imagem que a empresa projeta no mercado a auxilia na prática econômica, e constitui uma forma legítima de projetar seu trabalho, divulgar sua marca e seu produto.

Entretanto, a disciplina, uma das marcas da política do compliance, se desdobra do dever de aplicar medidas disciplinares quando houver a violação de regras de integridade. Essa previsão "é importante para garantir a seriedade do Programa, [...] Ainda mais importante é a certeza da aplicação das medidas previstas em caso de comprovação da ocorrência de irregularidades." (BRASIL, 2015, p. 22).

Para aplicação dessas sanções, estas já devem ser conhecidas e estar por escrito, além de prever as respectivas sanções, apontando quem serão os responsáveis pela apuração dos fatos, bem como qual procedimento seguir. Em relação às punições, essas devem ser proporcionais ao tipo de violação e ao nível de responsabilidade dos indivíduos, "deve existir também possibilidade de adoção de medidas cautelares, como o afastamento preventivo de dirigentes e funcionários que possam atrapalhar ou influenciar o adequado transcurso da apuração da denúncia." (BRASIL, 2015, p. 22). 
Importante mencionar que é necessário punir todos aqueles que praticaram os atos lesivos à corporação, independentemente da posição que ocupa da empresa, ou seja, a apuração dos fatos deve ser pautada na impessoalidade. Dessa forma, garante-se além da credibilidade das práticas de apuração de qualquer tipo de violação, a continuidade do engajamento de todos, o incentivo ao uso do canal de denúncias e a preservação e valorização da imagem da empresa tanto interna como externamente.

Entretanto, é interessante apostar na prevenção do cometimento dessas irregularidades para evitar a reincidência do problema e a ocorrência de novos focos que podem, com o tempo, se tornarem sistêmicos. Muitas empresas estão experimentando os programas de compliance com o intuito de melhorar suas atividades e fazer com que sejam bem-vistos no mercado. Muitas delas, inclusive, exibem com satisfação a conquista de selos de qualidade e procedência, e costumam utilizá-los para outras externalidades, como propagandas na perene competição para galgar colocação no mercado interno e externo.

A busca pela excelência se tornou uma prática incessante das empresas que, em seus segmentos, praticamente não subsistem quando não alcançam determinado selo de certificação, que nos dias atuais, entidades oferecem em diversas áreas, como selo verde, selo de sustentabilidade, selo empresa solidária, selo empresa amiga da criança, dentre outros. Cada um desses selos liga a atividade empresarial a um determinado preenchimento de requisito e assim projeta a imagem de acordo com o patamar de exigência alcançado.

Nesse passo, a necessidade de praticar atividade dentro dos parâmetros da ética e da transparência não nada mais é que o exercício de práticas de compliance. Não e demais investir na busca pela qualidade de seus serviços quando essa atitude reflete tanto na empresa e seus empregados, fornecedores, colaboradores, como também na sociedade, quando se busca cumprir com suas obrigações sociais, pagamento de tributos, cumprimento das leis trabalhistas. Essas conclusões que parecer ser apenas voltadas para empresa, irradiam sobremaneira na sociedade, compondo, assim, o conjunto de ações coordenadas e harmônicas que dão origem à função social da empresa.

\section{CONSIDERAÇÕES FINAIS}

Viu-se ao longo da pesquisa que as relações empresariais estão envoltas a diversos princípios que se entrelaçam e demandam dos envolvidos o engajamento necessário para que seja alcançada a função social/solidária da empresa. Esse foi o sentido encartado na Constituição Federal ao limitar as atividades empresariais sob o manto da garantia do exercício da propriedade privada. Se há razões para se preocupar com o alcance do déficit ético a ponto de buscar mecanismos para deter sua crescente, há razões a mais para que o compliance seja visto com bons olhos.

Na realidade não há nada de tormentoso nas boas práticas a serem implementadas diante de uma política de integridade proposta pelo compliance. Ao contrário, ajuda a traçar diretrizes concretas e modos de uso, condutas e soluções para diversos problemas nas corporações. Curioso ou não, o próprio poder público se mostra preocupado com a degradação ética de suas relações, a ponto de criar uma espécie de cartilha, o Programa de Integridade Diretrizes para empresas privadas, que associa diversas boas maneiras e como colocá-las em prática, numa espécie de manual de compliance para administração pública.

Essas são apenas indicações genéricas de como devem se comportar as empresas privadas diante de contratações com o poder público. Entretanto, restou evidenciado que o compliance é mais que isso: revela uma hipótese de adequação estrutural e conjuntural da 
forma como se deve proceder à diminuição do déficit ético de acordo com características próprias e peculiaridades de cada empresa.

Nesse sentido, a ética, como vetora de todas as ações num contexto da análise econômica do direito, exige que seja observada para auxílio no alcance de dar função social/solitária à empresa, fazendo parte, portanto, das limitações constitucionais a que a empresa, enquanto exercício da propriedade privada, está sujeita.

O compliance, nesse contexto, por ser ferramenta relativamente nova, apesar de já ter sido alvo de intensos debates no meio acadêmico, representa um inaudito leque de questionamentos e discussões, dado o dinamismo das atividades empresariais e os desafios que surgem a cada nova relação empresarial. As imposições do mercado internacional e a pressão do mercado interno fez com que as empresas buscassem aliar a busca do lucro, seu principal objetivo, com o bem-estar da sociedade, contribuindo para o alargamento dessas relações.

O exercício da atividade empresarial, diante das crises que enfrentamos, necessita cada vez mais ser pautado na ética e na boa-fé, na busca pelo desenvolvimento social e humano, como forma de cumprir a função social imposta constitucionalmente. É dizer que cada vez mais as empresas deverão estar comprometidas com a sociedade, como forma de diminuir as desigualdades sociais e a exclusão. Portanto, valorizar seus empregados, cumprir com suas obrigações fiscais, respeitar as normas trabalhistas e o meio ambiente, são ações que precisam ser feitas para compatibilizar o interesse privado com o coletivo e o difuso.

Outros sim, essa pesquisa não pretendeu esgotar o tema, mesmo porque, com o avanço da tecnologia, novas relações inclusive podem demandar uma reavaliação das diretrizes em busca do alcance da função social/solidária da empresa para o desenvolvimento social com o auxílio do compliance. A reafirmação de que são para o homem todos os esforços para preservação de sua dignidade não é um exagero: em tempos de paulatinas violações, preservar e reafirmar os direitos fundamentais ainda se mostra a melhor opção.

\section{REFERÊNCIAS}

ALZAGA VILLAAMIL, Oscar. Razón deSer. Revista de ResponsabilidadSocial dela Empresa, Madrid. n. 1, p. 9-11, jan./abr. 2009. Disponível em: <https://www.accioncontraelhambre.org/ sites/default/files/documents/10.pdf >. Acesso em: 19 out. 2018.

ALMEIDA, Maria Christina de. A função social da empresa na sociedade contemporânea: perspectivas e prospectivas. Revista Argumentum - RA, Marília/SP, v. 3, n. 1, p. 141-152, jan./ dez. 2003. Disponível em: <http://www.unimar.br/biblioteca/publicacoes/direito/Direito_ vol_03.pdf\#page=141>. Acesso em: o5 ago. 2018.

BARACHO, Hertha Urquiza; CECATO, Maria Aurea Baroni. Da função social da empresa à responsabilidade social: reflexos na comunidade e no meio ambiente. Revista Direito e Desenvolvimento, João Pessoa/PB, v. 7, n. 2, p. 114-128. Disponível em: <https://periodicos. unipe.br/index.php/direitoedesenvolvimento/article/view/320/300>. Acesso em: o6 ago. 2018.

BRASIL. Lei no 12.846, de 1ํㅡㄹ de agosto de 2013. Diário Oficial [da] República Federativa do Brasil, Brasília, DF. Disponível em <http://www.planalto.gov.br/ccivil_03/_ato2011-2014/2013/ lei/l12846.htm>. Acesso em: 18 jul. 2018. 
CARDOSO, Alenilton da Silva. Princípio da Solidariedade: Paradigma ético do direito contemporâneo. São Paulo: Juarez de Oliveira, 2010.

CARDOSO, Gleissa Mendonça Faria; CARMO, Valter Moura do. Função Social/Solidária da Empresa nos Negócios Virtuais. Revista Jurídica UNI7, Fortaleza, v. 14, n. 2, p. 137-157. jul./ dez. 2017. Disponível em: <www.uni7.edu.br/periodicos/index.php/revistajuridica/article/ view/509/371>. Acesso em: 25 abr. 2018.

DINIZ, Maria Helena. Curso de Direito Civil Brasileiro. Direito de Empresa. 4. ed. São Paulo: Saraiva, 2012.

FEITOSA, Maria Luiza Alencar Mayer. Exclusão social e pobreza nas interfaces entre o direito econômico do desenvolvimento e o direito humano ao desenvolvimento. In: SILVEIRA, Vladimir Oliveira da; SANCHES, Samyra Naspolini; COUTO, Monica Benetti (Org.). NETO, Aristides Monteiro; MEDEIROS, Bernardo Abreu de (Coord.). Direito e desenvolvimento no Brasil do século XXI. Brasília: Ipea; Florianópolis: CONPEDI, p. 104-121, 2013.

FURTADO, Emmanuel. O princípio constitucional da dignidade da pessoa humana como fundamento para preservação da identidade cultura. In: TRINDADE, Antonio Augusto Cançado; LEAL, César Barros (Coord.). O respeito à dignidade da pessoa humana. Curso Brasileiro Interdisciplinar em Direitos Humanos. v. IV. Fortaleza: Expressão Gráfica, p. 281-316, 2015 .

GABARDO, Emerson; CASTELLA, Gabriel Morettini. A nova lei anticorrupção e a importância do compliance para as empresas que se relacionam com a Administração Pública. A\&C - Revista de Direito Administrativo \& Constitucional, Belo Horizonte, ano 15, n. 6o, p. 129-147, abr./ jun. 2015. Disponível em: <http://www.editoraforum.com.br/wp-content/uploads/2015/o8/leianticorrupcao-compliance.pdf $>$. Acesso em: 5 jun. 2018.

GONÇALVES, Daniela Oliveira; REZENDE, Elcio Nacur. Função socioambiental da propriedade: a busca por uma determinação pragmática de aferição de cumprimento. Revista da Faculdade de Direito-RFD-UERJ, Rio de Janeiro, n. 28, p. 52-72, dez. 2015. Disponível em: <http://www.e-publicacoes.uerj.br/index.php/rfduerj/article/view/10597/14646>. Acesso em: 06 ago. 2018.

GRANDIS, Simone de. Responsabilidade Social Empresarial frente às boas práticas de Compliance. LEC Legal, Ethics \& Compliance, 11 jul. 2017. Disponível em: <http://www. lecnews.com/artigos/2017/07/11/responsabilidade-social-empresarial-frente-as-boas-praticasde-compliance/>. Acesso em: og jul. 2018.

MENDES, Francisco Schertel; CARVALHO, Vinicius Marques de. Compliance, concorrência e combate à corrupção. São Paulo: Trevisan, 2017.

LANDA, César. Dignidad de la persona humana. In: TRINDADE, Antonio Augusto Cançado; LEAL, César Barros. (Coord.). El respeto a la dignidad de la persona humana. Curso Brasileño Interdisciplinario en Derechos Humanos. v. IV. Fortaleza: Expressão Gráfica, 2015. p. 107-138. 
NOGUEIRA, Arnaldo Fernandes; BENEVIDES, Marinina Gruska. A consolidação dos Direitos Humanos. Revista do Instituto Brasileiro de Direitos Humanos, Fortaleza, n. 16, nov. 2017. Disponível em: <http://revista.ibdh.org.br/index.php/ibdh/article/view/343>. Acesso em: 10 jul. 2018.

PEREIRA JÚNIOR, Jessé Torres; MARÇAL, Thaís Boia. Compliance: análise jurídica da economia. LEC Legal, Ethics \& Compliance, 31 mar. 2017. Disponível em: <http://www. lecnews.com/artigos/2017/03/31/compliance-analise-juridica-da-economia/>. Acesso em: 5 jun. 2018.

PESSOA, Emanuel de Abreu. A Constitucionalização da Função Social da Propriedade: Alteração na Dogmática do Direito Civil. Revista Jurídica UNI7, Fortaleza, v. 7, p. 65-75. jan./dez. 2010. Disponível em: <http://www.uni7.edu.br/periodicos/index.php/revistajuridica/ article/view/137/159>. Acesso em: 05 ago. 2018.

RODRIGUES, Francisco Luciano Lima; LIMA, Martonio Mont'Alverne Barreto. O princípio constitucional da dignidade da pessoa humana como fundamento para preservação da identidade cultural. In: TRINDADE, Antonio Augusto Cançado; LEAL, César Barros. (Coord.). $O$ respeito à dignidade da pessoa humana. Curso Brasileiro Interdisciplinar em Direitos Humanos. v. IV. Fortaleza: Expressão Gráfica, p. 339-352, 2015.

ROTSCH, Thomas. Criminal Compliance. Revista para el analisis del derecho. Barcelona, n. 1, p. o1-11, 2012. Disponível em: <http://www.indret.com/pdf/876a.pdf>. Acesso em: 19 out. 2018.

SANTIAGO, Mariana Ribeiro; CAMPELLO, Livia Gaigher Bósio. Função social e solidária da empresa na dinâmica da sociedade de consumo. Scientia Iuris, Londrina, v.2o, n.1, p.119-143, abr. 2016. Disponível em: <http://www.uel.br/revistas/uel/index.php/iuris/article/ view/19877/18798>. Acesso em: o5 ago. 2018.

SARLET, Ingo Wolfgang. As dimensões da dignidade da pessoa humana: construindo uma compreensão jurídico-constitucional necessária e possível. Revista Brasileira de Direito Constitucional. v. 1, n. 9, jan./jun. 2007. Disponível em: <http://www.esdc.com.br/RBDC/ RBDC-09/RBDC-09-361-Ingo_Wolfgang_Sarlet.pdf>. Acesso em: 16 out. 2018.

SILVEIRA, Vladimir Oliveira da; RIBEIRO, Elenice Baleeiro Nascimento. Ética: Conteúdo da Responsabilidade Corporativa e Desdobramento da Função Solidária da Empresa. Revista Argumentum - RA, Marília/SP, v. 16, n. 1, p. 37-54, jan./dez. 2015. Disponível em: <http://ojs. unimar.br/index.php/revistaargumentum/article/view/191/38>. Acesso em: 10 jul. 2018.

. NASPOLINI, Samyra Haydêe Dal Farra. Direito e desenvolvimento no brasil do século XXI: uma análise da normatização internacional e da constituição brasileira. In: SILVEIRA, Vladmir Oliveira da; SANCHES, Samyra Naspolini; COUTO, Monica Benetti (Org.). NETO, Aristides Monteiro; MEDEIROS, Bernardo Abreu de (coord.). Direito e desenvolvimento no Brasil do século XXI. Brasília: Ipea, CONPEDI, p. 123-150, 2013. 
XAVIER, Christiano Pires Guerra. Programas de compliance anticorrupção no contexto da Lei 12.846/13: elementos e estudo de caso. 2015. $100 \mathrm{f}$. Dissertação (mestrado em Direito) - Escola de Direito de São Paulo da Fundação Getúlio Vargas. São Paulo, 2015. Disponível em: <https://bibliotecadigital.fgv.br/dspace/bitstream/handle/10438/13726/Dissertação\%20-\%20 Versão\%2oFinal\%204.pdf?sequence=1\&isAllowed $=y>$. Acesso em: 05 ago. 2018. 